\title{
MODELING THE EFFECTIVE ELASTIC MODULUS OF RC BEAMS EXPOSED TO FIRE
}

\author{
Jui-Hsiang Hsu \\ University, jhhsu@cyu.edu.tw \\ Cherng-Shing Lin \\ Professor, Department of Mechanical Engineering, Yuan Ze University. \\ Chang-Bin Huang \\ Ph.D candidate of Mechanical Engineering, Yuan Ze University
}

Instructor, Department of Civil Engineering, Ching Yun University. Ph.D candidate of Mechanical Engineering, Yuan Ze

Follow this and additional works at: https://jmstt.ntou.edu.tw/journal

Part of the Civil and Environmental Engineering Commons

\section{Recommended Citation}

Hsu, Jui-Hsiang; Lin, Cherng-Shing; and Huang, Chang-Bin (2006) "MODELING THE EFFECTIVE ELASTIC MODULUS OF RC BEAMS EXPOSED TO FIRE," Journal of Marine Science and Technology. Vol. 14: Iss. 2, Article 5.

DOI: $10.51400 / 2709-6998.2063$

Available at: https://jmstt.ntou.edu.tw/journal/vol14/iss2/5

This Research Article is brought to you for free and open access by Journal of Marine Science and Technology. It has been accepted for inclusion in Journal of Marine Science and Technology by an authorized editor of Journal of Marine Science and Technology. 


\title{
MODELING THE EFFECTIVE ELASTIC MODULUS OF RC BEAMS EXPOSED TO FIRE
}

\author{
Jui-Hsiang Hsu*,***, Cherng-Shing Lin**, and Chang-Bin Huang***
}

Key words: modeling, effective, elastic modulus, $\mathrm{RC}$ beams, fire.

\begin{abstract}
This work combines thermal and structural analyses to study the effect of fire on the elastic modulus of reinforced concrete beams. The thermal analysis uses the finite difference method to model the temperature distribution of a reinforced concrete beam maintained at high temperature. The structural analysis, using the lumped method, is utilized to calculate the effective elastic modulus of reinforced concrete beams. The results of the thermal analysis are compared to the experimental results in the literature, and the analytically derived structural results are also compared with experimental data on the flexural behaviors of RC beams exposed to fire. The predicted and experimental temperature distribution in the concrete beam and deformation in the structural model agree with each other. The findings provide important information on the flexural behavior of $\mathrm{BC}$ beams exposed to fire.
\end{abstract}

\section{INTRODUCTION}

Population densities are typically high in urban areas, including in cities in Taiwan. More than $90 \%$ of the buildings in Taiwan use reinforced concrete (RC) structures and on average 10,000 fires occur annually. Following fire damage, whether the RC structures are sufficiently safe must be determined to protect human life and property. The fire safety of any RC structure depends strongly on its resistance to fire, which in turn depends on the combustibility and fire resistance of its main structural elements, beams and columns. No two fires are the same so modeling must be employed to study the behavior of RC beams exposed to fire.

During a building fire, different parts of a beam's cross-section are exposed to different temperatures. Heating considerably changes the strength, physical properties and stiffness of both concrete and steel. The

Paper Submitted 06/29/05, Accepted 11/02/05. Author for Correspondence: Jui-Hsiang Hsu.E-mail: jhhsu@cyu.edu.tw.

*Instructor, Department of Civil Engineering, Ching Yun University.

**Professor, Department of Mechanical Engineering, Yuan Ze University.

***Ph.D candidate of Mechanical Engineering, Yuan Ze University. modulus of elasticity decreases as the temperature increases [5]. Investigations [9-11] were conducted to study the effect of high temperature on the properties of concrete. References $[11,12]$ present the effect of high temperature on the characteristics of steel. Therefore, concrete and steel reinforcement bars in the beams have heterogeneous characteristics. Predicting these changes is critical in assessing the performance of structures after they have been exposed to fire.

Analyzing the mechanical properties of RC elements after they have been exposed to high temperature for a long period requires knowledge of the temperature distribution in the cross-sections. This is obtained from the thermal properties of the material, including the heat capacity and the thermal conductivity. This work aims to model temperature distributions in rectangular concrete beams. The results are compared to and verified by experimental results of Lin [7].

In the structural analysis, the cross-section of an $\mathrm{RC}$ beam is divided into $M \times N$ segments. Each segment is treated as having a uniform (but different) temperature and iso-properties, based on the lumped system concept. Then, the variations in the elastic modulus of each segment associated with the different temperatures in concrete and reinforcing steels are determined, and the effective elastic modulus of the RC beams is determined using the interface layer method [14]. The calculated results are confirmed by the experimental flexural behavior of the RC beams that have been exposed to fire for various periods [8].

This work proposes an engineering model of the effective elastic modulus of RC beams exposed to fire. The predictions agree closely with the experimental results and help in understanding the effect of fire on the flexural behavior of RC beams. The elastic moduli of structural elements influence the values of moment distribution in the structural calculation. Modeling the residual elastic modulus of $\mathrm{RC}$ beams that are exposed to fire helps to understand the moment re-distribution after fire takes place. As fires are never the same, this study manages to construct a framework to model arbitrary kind of fire damage scenario. 


\section{TEMPERATURE ANALYSIS}

In a real fire, or a fire test, heat will flow to the surface of the structure exposed to fire by means of radiation and convection. The heat will then be transferred internally away from the surface by means of conduction. Because of the time dependency of the gas temperature, this heat transfer is classified as a "transient" temperature analysis problem.

Accurately predicting the temperature variation within the structural element with time is essential for determining the corresponding material properties at the relevant temperatures, and carrying out the structural analysis. The Finite Difference Method (FDM) is used in the temperature distributions analysis. The fundamental equation that represents transient heat conduction in a solid under the continuity condition is typically presented in its well-known differential form

$$
\rho(T) c(T) \frac{\partial T}{\partial t}+\nabla \cdot q^{\prime \prime}=u^{\prime \prime}
$$

where

$$
\begin{aligned}
& \rho(T)=\text { density of the material } \\
& c(T)=\text { specific heat of the material } \\
& T=\text { field variable, or temperature } \\
& t=\text { time variable } \\
& u^{\prime \prime \prime}=\text { rate of local heat source per unit volume }
\end{aligned}
$$

The density of concrete depends on the aggregate and mixed design. Typical 'dense' concrete has density of about $2300 \mathrm{~kg} / \mathrm{m}^{3}$. When concretes are heated to 100 , most of their densities reduce by up to $100 \mathrm{~kg} / \mathrm{m}^{3}$ due to the evaporation of free water, which has a minor effect on thermal response. Besides moisture changes, the density of concrete does not change much at elevated temperature, except for calcareous aggregate concrete which decomposes at about $800^{\circ} \mathrm{C}$ with a corresponding sudden decrease in density [1]. In this modeling, the density of concrete used the constant value of $2300 \mathrm{~kg} / \mathrm{m}^{3}$. The specific heat of concrete for anorthosite and expanded shale aggregates, calculated by Harmathy [6], increased smoothly from $0.71 \mathrm{~kJ} / \mathrm{kg} K$ at $25^{\circ} \mathrm{C}$ to $1.22 \mathrm{~kJ} / \mathrm{kg} K$ at $1000^{\circ} \mathrm{C}$.

Furthermore, $\boldsymbol{q}^{\prime \prime}$ in Eq. (1) is the heat flux through the volume, and can be represented as the Fourier law of conduction in a vector relationship involves all three directions:

$$
\boldsymbol{q}^{\prime \prime}=q_{x}^{\prime \prime} \boldsymbol{i}+q_{y}^{\prime \prime} \boldsymbol{j}+q_{z}^{\prime \prime} \boldsymbol{k}=-k(T)\left(\frac{\partial T}{\partial x} \boldsymbol{i}+\frac{\partial T}{\partial y} \boldsymbol{j}+\frac{\partial T}{\partial z} \boldsymbol{k}\right)
$$

or

$$
\boldsymbol{q}^{\prime \prime}=-k(T) \nabla T
$$

where $k(T)$ denotes the thermal conductivity of the material. Substituting Eq. (2) into Eq. (1) and assuming no heat source exists within the volume, the equation can be expressed as

$$
\begin{aligned}
\rho(T) c(T) \frac{\partial T}{\partial t} & =\frac{\partial}{\partial x}\left(k(T) \frac{\partial T}{\partial x}\right)+\frac{\partial}{\partial y}\left(k(T) \frac{\partial T}{\partial y}\right) \\
& +\frac{\partial}{\partial z}\left(k(T) \frac{\partial T}{\partial z}\right)
\end{aligned}
$$

By assigning suitable initial and boundary conditions Eq. (3) describes the temperature distribution at any time and at any point of the considered volume.

This work utilizes the Finite Difference Method to solve Eq. (3) and presents the various temperature distributions of reinforced concrete beam that is maintained at a high temperature. Figure 1 shows the flowchart of the proposed calculating algorithm.

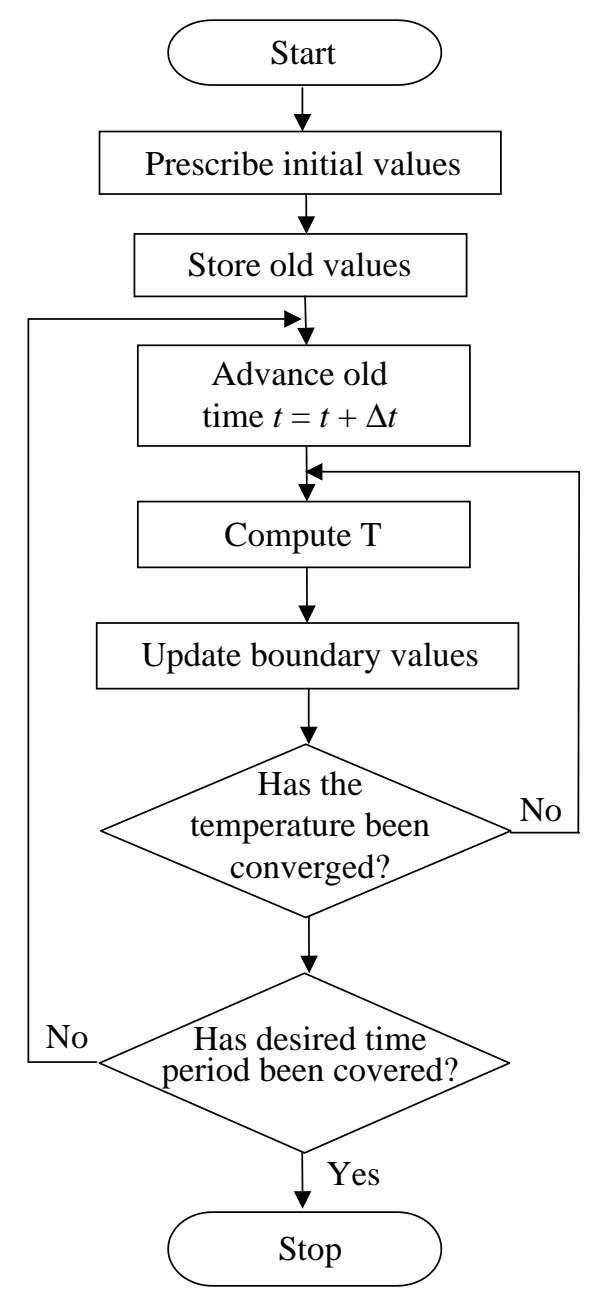

Fig. 1. Flowchart for calculating temperature distribution of a beam exposed fire. 


\section{STRUCTURAL ANALYSIS}

This work considers the fire-related factors that affect reinforcement bars and concrete materials, using the lumped system method, and determines the effective elastic modulus of the RC beam after it has been damaged by fire.

The lumped system concept is taken from thermal conduction models. When heat is transferred through a medium, the temperature varies with time and position. Under particular conditions, temperature varies only linearly with time; such a system is called a "Lumped System" [13]. The concept of the original lumped system is extended such that, following separation, the temperature and mechanical characteristics of the material do not vary with position. The temperature and mechanical properties of the unit are assumed to be everywhere the same as those at the center of the unit. In this work, the cross-section of an RC beam is divided into $M \times N$ segments for analysis. Each segment is considered to have a uniform (but different) temperature and iso-properties, according to the lumped system concept.

The effects of temperature on the elastic modulus of concrete and the reinforcing bars must be known to model the effective elastic modulus of R.C. beams exposed to fire. The reduction in the modulus of elasticity of the reinforcing bars with temperature is specified by [14]

$$
\begin{aligned}
k_{E . T} & =1.0+T /[2000 \ln (T / 1100)] 0<\mathrm{T} \leq 600^{\circ} \mathrm{C} \\
& =690(1-T / 1000) /(\mathrm{T}-53.5) 600^{\circ} \mathrm{C}<\mathrm{T} \leq 1000^{\circ} \mathrm{C}
\end{aligned}
$$

where $k_{E T}$ is the ratio of $E_{T}$ (the modulus of elasticity at elevated temperature) to $E$ (the modulus of elasticity at $20^{\circ} \mathrm{C}$ )

The modulus of elasticity of concrete also decreases as the temperature increases. The reduction ratio given in EC2 [3] is,

$$
\begin{aligned}
& k_{E . T}=1.0 \text { for } T<150^{\circ} \mathrm{C} \\
& k_{E . T}=(700-T) / 550 \text { for } T \geq 150^{\circ} \mathrm{C}
\end{aligned}
$$

In this work, the cross-section of an RC beam is divided into $M \times N$ segments for analysis. Each segment is considered to have a uniform (but different) temperature and iso-properties, based on the lumped system concept. The approximate engineering formulas for determining the effective elastic modulus of the reinforced concrete beam is obtained as follow by the interface layer approach [14].

For a beam (as shown in Figure 2), the effective elastic modulus of every horizontal strip (each with $M$ parallel strips) was determined first. For parallel strips with various $e_{i j}$ values, as presented in Figure 3 , the effective elastic modulus $e_{J}$ of the combined body is obtained from the compatibility of their longitudinal deformations under loading (each strip has a different stress). The effective elastic modulus of horizontal strip $J$ may be formulated as,

$$
\begin{aligned}
e_{j} & =\sum_{i=1}^{M} e_{i j} \frac{v_{i j}}{\sum_{i=1}^{M} v_{i j}}=e_{1 j} \frac{v_{1 j}}{v_{1 j}+v_{2 j}+v_{3 j}+\cdots} \\
& +e_{2 j} \frac{v_{2 j}}{v_{1 j}+v_{2 j}+v_{3 j}+\cdots}+\cdots
\end{aligned}
$$

where $e_{i j}$ and $v_{i j}(i=1,2,3 \ldots)$ are the elastic modulus and volume of each parallel strip in the horizontal strip
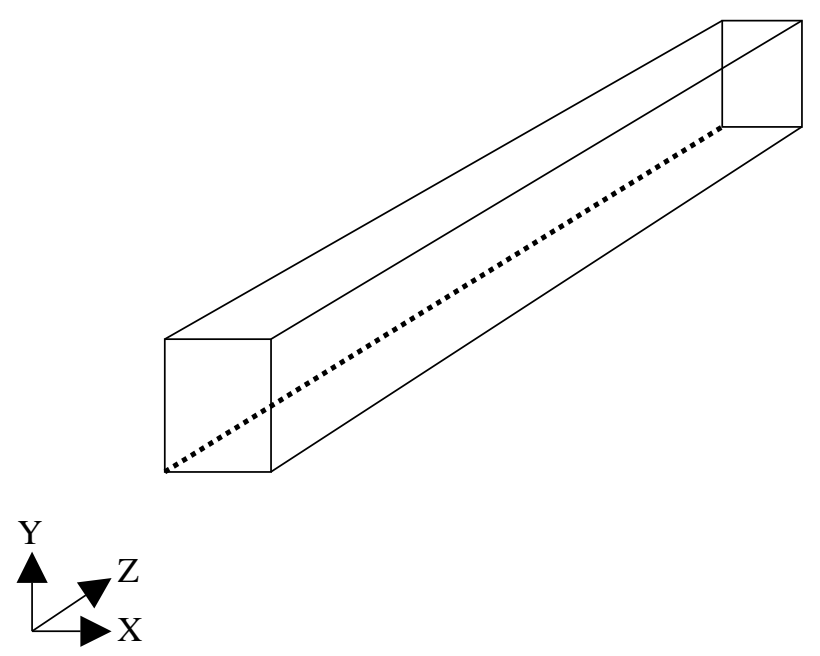

Fig. 2. Beam coordinates.

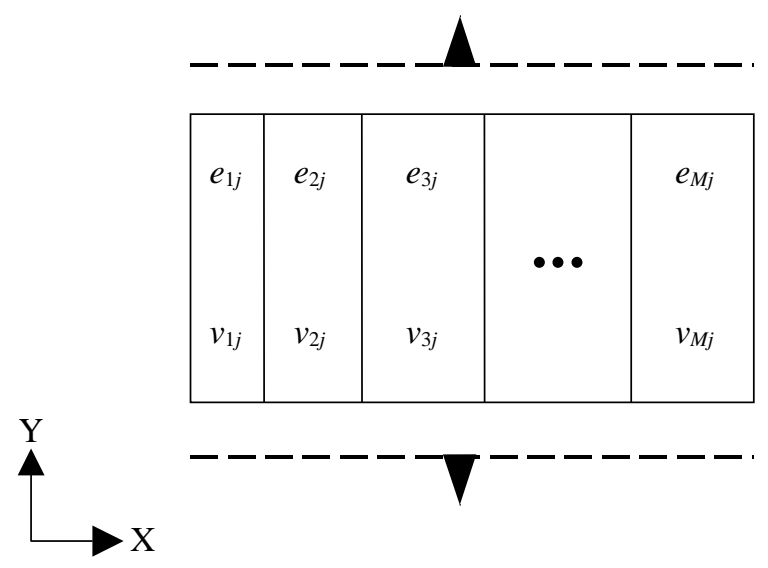

Fig. 3. Horizontal strip $J$ (with different parallel elastic modulus). 
$J$, respectively.

For horizontal strips with various $e_{J}$ values, as shown in Figure 4 and based on engineering mechanics, we obtain an effective elastic modulus $E_{e}$ of this combined body assuming a uniform stress in vertical direction (each strip has a different deformation).

$$
\begin{aligned}
& E_{e}=\frac{1}{\sum_{J=1}^{N} \frac{V_{J}}{e_{J} \sum_{J=1}^{N} V_{J}}} \\
& =\frac{1}{\frac{V_{1}}{e_{1}\left(V_{1}+V_{2}+V_{3}+\cdots\right)}+\frac{V_{2}}{e_{2}\left(V_{1}+V_{2}+V_{3}+\cdots\right)}+\cdots}
\end{aligned}
$$

where $e_{J}$ and $V_{J}(J=1,2,3 \ldots)$ are the effective elastic modulus and volume of each of the horizontal strips, and $E_{e}$ is the effective elastic modulus of the beam.

\section{RESULTS AND DISCUSSION}

Lin [7] conducted studies on the temperature distribution of pure concrete materials during fire. For the convenience of comparison, the dimensions $304.8 \mathrm{~mm}$ $\times 416.4 \mathrm{~mm}(12 \mathrm{in} \times 16 \mathrm{in})$, which were used by Lin [7], were used to simulate the temperature distributions of

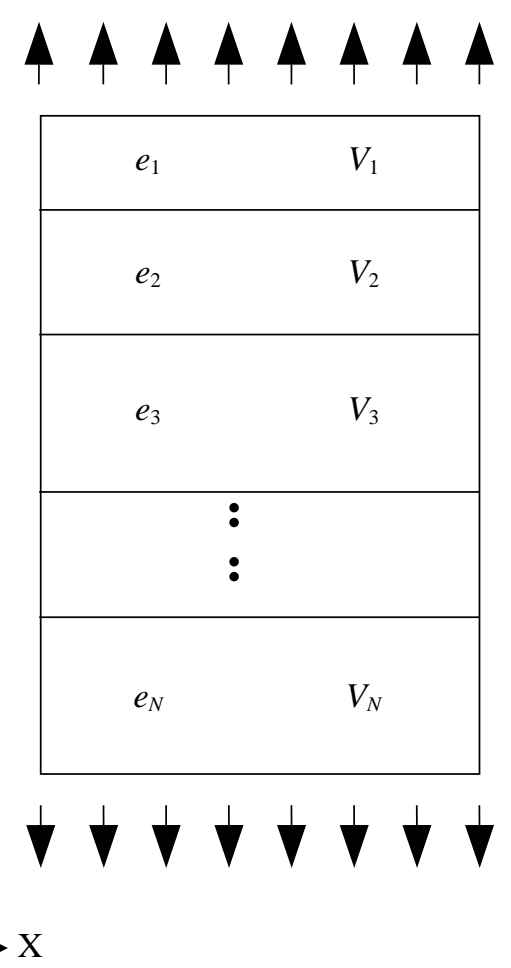

Fig. 4. Parallel strip (with different horizontal elastic modulus). the beam cross-section of which three surfaces were exposed to fire, under the ASTM E 119 standard temperature-rise curve [2]. Figure 5 plots the isothermal

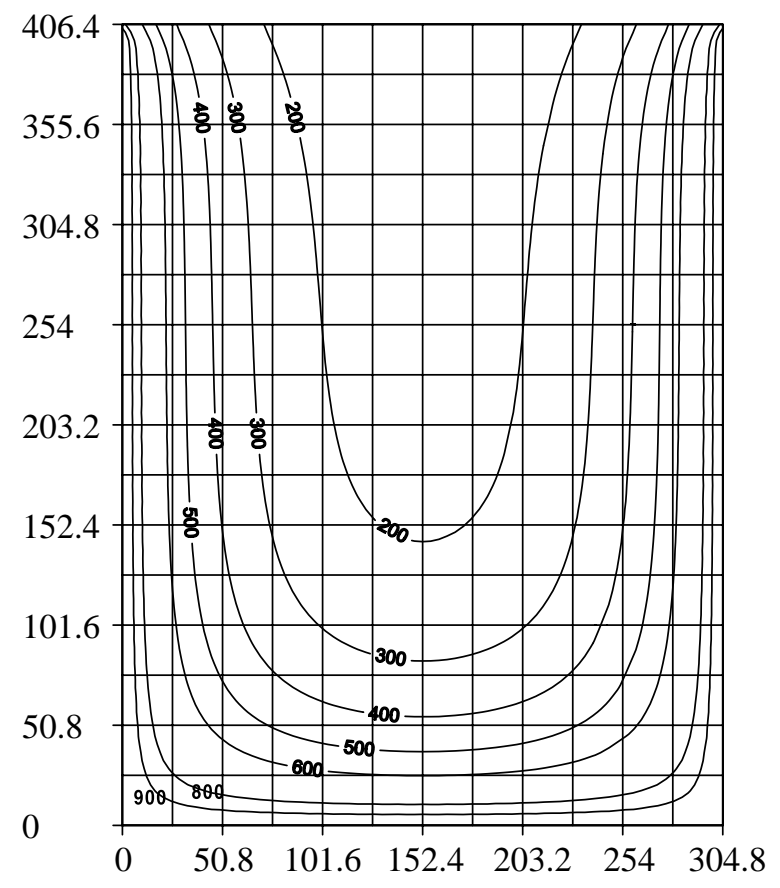

(a) Fire during of 2 hours

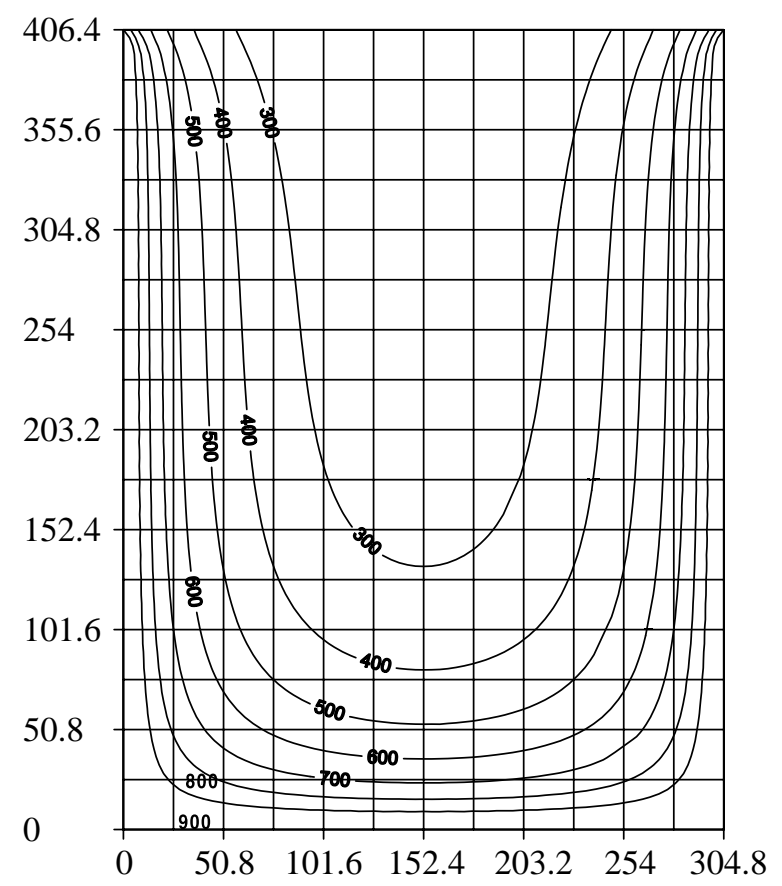

(b) Fire during of 3 hours

Fig. 5. Compare results with isothermal counters of concrete beam during fire damage, left side are from this simulated and right side is experiment result from Lin [7]. 
Table 1. Effective elastic modulus

\begin{tabular}{|c|c|c|c|c|}
\hline \multirow[b]{2}{*}{ Properties } & \multicolumn{4}{|c|}{ Beam } \\
\hline & $\mathrm{B}$ & B1 & $\mathrm{B} 2$ & B3 \\
\hline Fire exposure time (min.) & 0 & 30 & 60 & 120 \\
\hline Effective elastic modulus (Mpa) & 21,578 & 14,703 & 11,233 & 8,097 \\
\hline
\end{tabular}

$* E_{c}=2.06 \times 10^{4} \mathrm{Mpa} ; E_{s}=1.99 \times 10^{5} \mathrm{Mpa}$.

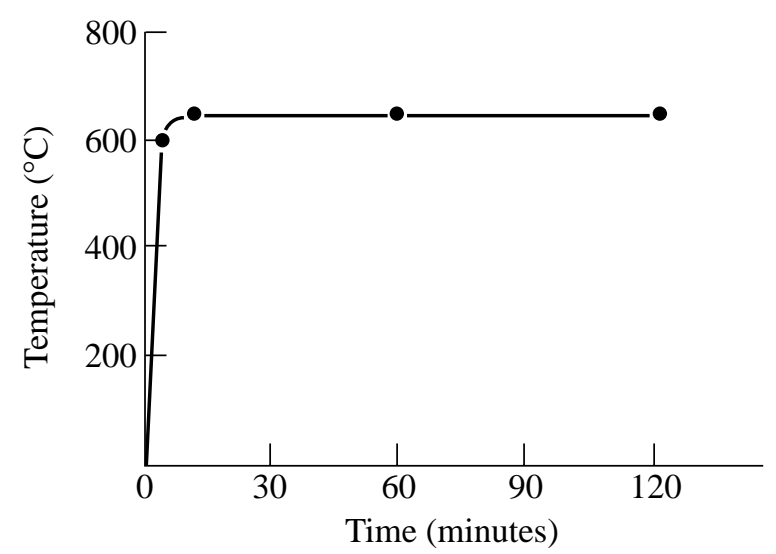

Fig. 6. Time-temperature curve.

contours, and a comparison made with the measurements of Lin [7]. The left-hand side of Figure 5 is the isotherm obtained by simulation, while the right-hand side is the isotherm of Lin. A very close match is generally found between isotherms during the two-hour fires, and a similar match is observed for isotherms following the three-hour fires, with the small exception for a small deviation in the $500 \sim 600^{\circ} \mathrm{C}$ range.

Moetaz et al. [8] fabricated four reinforced beams with a depth of $200 \mathrm{~mm}$, a width of $120 \mathrm{~mm}$, and a length of $1,800 \mathrm{~mm}$. The beams were reinforced with $2 \psi 10$ $\mathrm{mm}$ (two, $10 \mathrm{~mm}$ diameter bars) grade 52 steel as the main reinforcement, $2 \psi 10 \mathrm{~mm}$ grade 37 steel as the secondary reinforcement, and $\psi 8 \mathrm{~mm}$ grade 37 stirrups with $8 \mathrm{~cm}$ spacing. The beams were installed in the fire test chamber 40 days after casting. During the fire test, the beams were not loaded and exposed to fire at $650^{\circ} \mathrm{C}$ (Figure 6). The chamber was controlled so that the same average temperature-time curve was followed for all beams. Beams were exposed to fire for 30, 60 and 120 minutes and the control beam was not exposed to fire. The beams were then tested in flexure by applying two increasing transverse loads (Figure 7) after they have been cooled to room temperature. Strains and deflections were measured at each load increment. The relationships between the load and the maximum deflections of the tested beams, for all beams, are almost

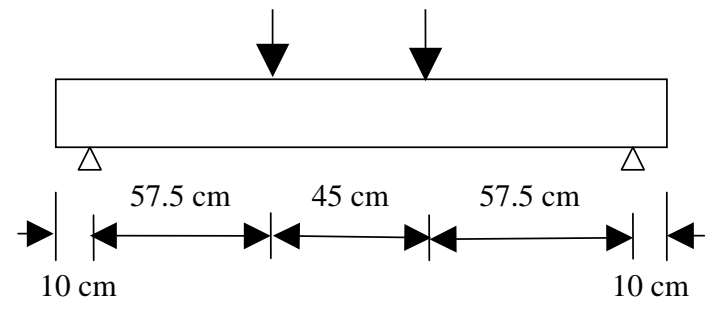

Fig. 7. Fire flexural test conditions.

linear and the slopes of the lines decrease as the period of exposure to fire increases [8].

This study implements the experimental program in reference [8] and adds the boundary temperaturetime curve into the temperature distribution simulation in the last section. The temperature of each segment in the section of the RC beams is thus obtained. Eq. (7) yields the effective elastic modulus of reinforced concrete beams exposed to fire. Table 1 presents the calculated effective elastic modulus following exposure to fire for $0,30,60$ and 120 minutes. The results indicate that the effective elastic moduli of beams $B_{1}$, $\mathrm{B}_{2}$ and $\mathrm{B}_{3}$ were $31.9 \%, 47.9 \%$ and $62.5 \%$ less than those of reference beam (B). According to beam theory, the deflection curve equation, loaded like Figure 7 , cans similar presenting as,

$$
\frac{d^{2} y}{d x^{2}}=\frac{M}{E I}=\frac{57.5 P}{E I}
$$

where $E\left(\mathrm{~kg} / \mathrm{cm}^{2}\right)$ and $I\left(\mathrm{~cm}^{4}\right)$ are, respectively, the elastic modulus and moment of inertia of the beam section, and $\mathrm{P}$ represents the load. The double-integration method involves the double integrals in Eq. (8). It is used with the calculation of the integral coefficients from the boundary conditions, to yield the deflections as,

$$
y=\frac{P}{E I}\left(\frac{57.5}{2} x^{2}-4600 x\right)=\frac{P}{E I}(-184000)
$$

The maximum deflection of the RC beams, after exposed to fire, can be determined from Eq. (9) at the mid-span. The calculated load-maximum deflection relations are compared with the test results for beams 


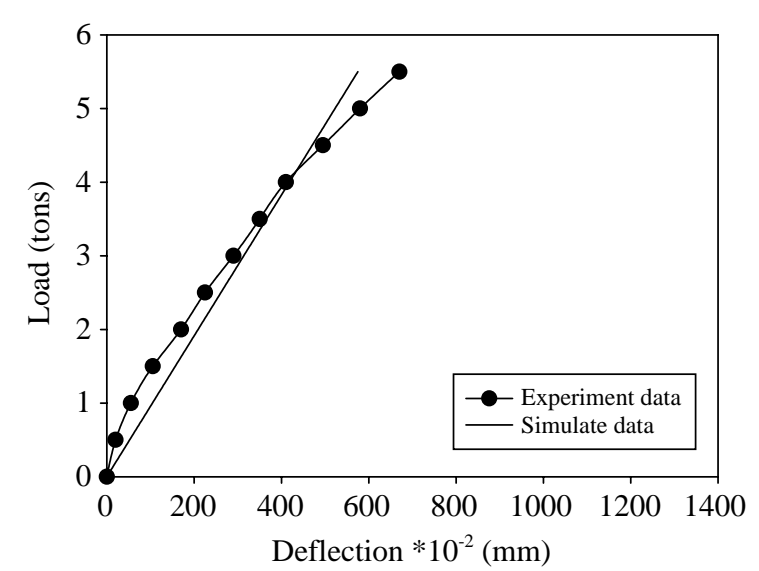

Fig. 8. Comparison between experimental and calculated data for the reference beam $B$ (no exposure).

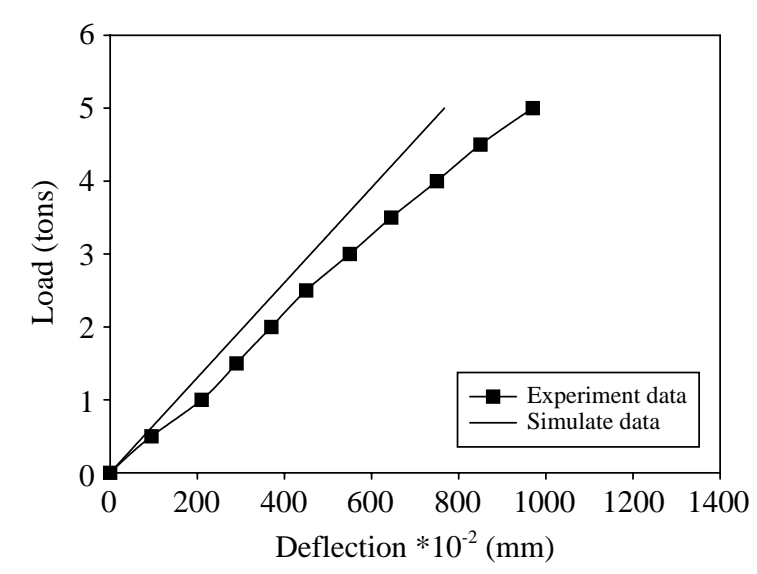

Fig. 9. Comparison between experimental and calculated data for the beam $\mathrm{B} 1$ (exposed $30 \mathrm{~min}$.).

that had been exposed to fire for $0,30,60$ and 120 minutes. Figure 8 compares the load-maximum deflection relations of experimental results with calculated data for reference beam. The slopes of the experimental curve decrease as the load increases, but they are not far from the calculated results. Figure 9 reveals that the calculated and experimental results have a little departure after exposure to fire for 30 minutes. They fit each other closely when the beams have been exposed to fire for 60 minutes (Figure 10). Figure 11 shows that the calculated results start to deviate from experimental data after 120 minutes of exposure. The slopes of experimental Load- Deflection curves, from Figures 8 to 11 , have the shift to decrease when load is increasing. Its means the elastic modulus decrease when load increase. This result indicated that the tensional side of the beam section may start to crack when load is increasing. This study mathematically characterizes

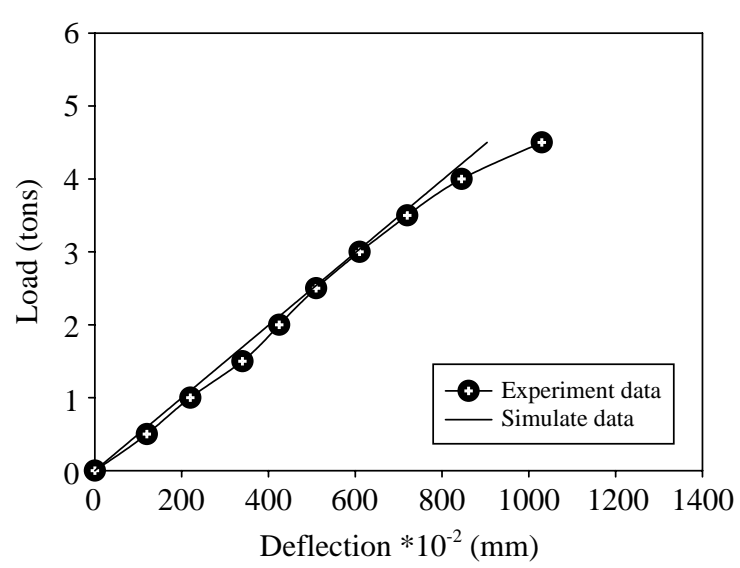

Fig. 10. Comparison between experimental and calculated data for the beam $B 2$ (exposed $60 \mathrm{~min}$.).

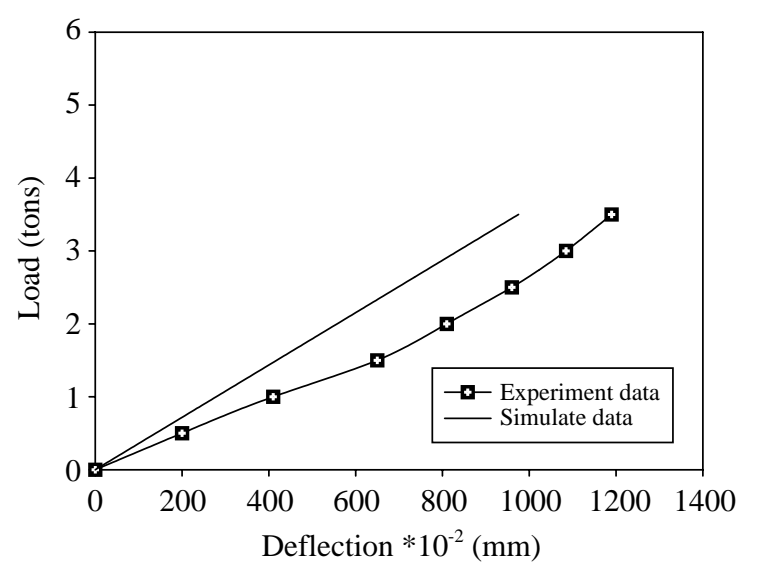

Fig. 11. Comparison between experimental and calculated data for the beam B3 (exposed 120 min.).

the relation between load and maximum deflection of beams that with $2 \mathrm{~cm}$ decrease of depth (have $2 \mathrm{~cm}$ of crack) and get exposed fire for 120 minutes long. A comparison between experimental and analytically calculated data can be seen in Figure 12, which displays more consistency than the results shown in Figure 11. This indicates that long-term fire damage may have destroyed the structure of the beam. The predicted effective elastic moduli of beams exposed to fire for a relatively long period typically exceed the actual values and the proposed modeling should be applied more conservatively in such a case.

\section{CONCLUSION}

This study includes a general analytical model of the effective elastic modulus of the RC beams exposed to fire. The following conclusions are drawn. 


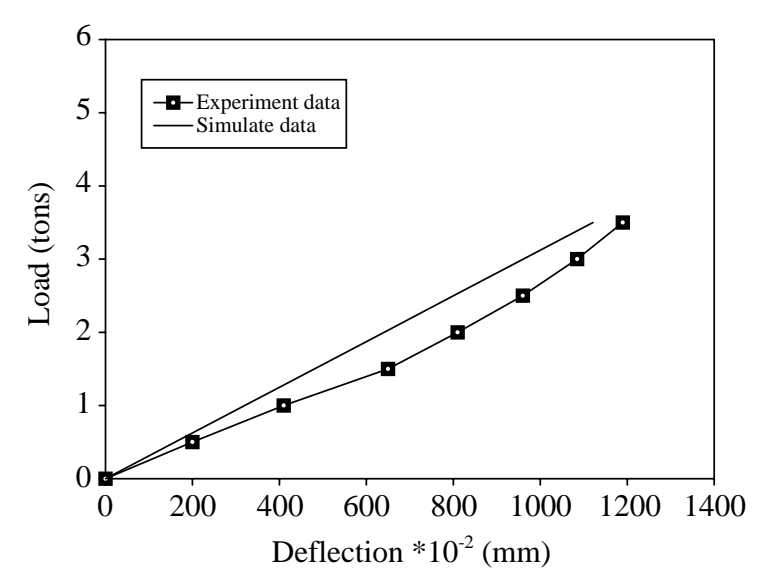

Fig. 12. Comparison between experimental and calculated data for the beam B3 with $2 \mathrm{~cm}$ cracked (exposed $120 \mathrm{~min}$.).

1. Fires can damage structures. The behavior of structures exposed to fire must be modeled. The effective elastic modulus of RC beams with fire damage was successfully modeled and predicted herein. The results are very helpful in understanding the deformation characteristics of structures exposed to fire.

2. The effective elastic moduli of beams exposed to fire for 30, 60 and 120 minutes are around $31.9 \%, 47.9 \%$ and $62.5 \%$ less than that of the reference beam, respectively.

3. The calculation in this model assumes that the beam section remains complete (no crack) after fire damage. When cracks are observed in the beam section after fire damage, the legitimacy of using this model should be carefully evaluated.

4. The predicted effective elastic moduli of beams exposed to fire for relatively long periods begin to deviate from the experimental values and generally exceed the actual values. In this case, the proposed model should be used more conservatively.

\section{REFERENCES}

1. Andrew, H.B., Structure Design for Fire Safety, John Wiley \& Sons, New York (2000).
2. ASTM E05.11 Task Group, Repeatability and Reproducibility of Results of ASTM E 119 Fire Test (Research Report No. RR: E5-1003), ASTM, Philadelphia, PA (1982).

3. European Committee for Standardization, Design of Steel Structures ENV 1992-1-2: General Rules-Structural Fire Design (EC2 Eurocode 2), Brussels, Belgium (1993).

4. European Committee for Standardization, Design of Steel Structures ENV 1993-1-2: General Rules-Structural Fire Design (EC3 Eurocode 3), Brussels, Belgium (1995).

5. Gruz, C.R., "Elastic Properties of Concrete at High Temperature," Journal of the PCA Research and Development Laboratories, Vol. 8, No. 1, pp. 37-45(1966).

6. Harmathy, T.Z., "Thermal Properties of Concrete at Elevated Temperatures," ASTM Journal of Materials, Vol. 5, No. 1, pp. 47-74 (1970).

7. Lin, T.D., "Measured Temperature in Concrete Beams Exposed to ASTM E 119 Standard Fire," Research and Development Report, Portland Cement Association, Skokie (1985).

8. Moetaz, M.E., Ahmed, M.R., and Shadia, E., "Effect of Fire on Flexural Behavior of RC Beams," Construction and Building Materials, Vol. 10, No. 2, pp. 147-150 (1996).

9. Neville, A.M., Properties of Concrete, John Wiley \& Son, London (1995).

10. Robert, P., "Some Physical Properties of Concrete at High Temperature," Journal of the American Concrete Institute, Vol. 54, No. 10, pp. 857-864 (1958).

11. Smith, E.E. and Harmathy, T.Z., Design of Building for Fire Safety, American Society for Testing and Materials, Philadelphia, PA (1979).

12. Uddin, T. and Culver, C.G., "Effect of Elevated Temperature on Structure Menbers," Journal of the Structural Dirision-ASCE, Vol. 101, pp. 1531-1549 (1975).

13. Yunus, A.Ç., Heat Transfer: a Practical Approach, McGraw-Hill, New York (1998).

14. Zhao, X.H. and Chen, W.F., "Effective Elastic Moduli of Concrete with Interface Layer," Computers \& Structures, Vol. 66. No. 2-3, pp. 275-288(1998). 